\title{
Pruebas de laboratorio COVID-19 y su implicación en el tratamiento dental
}

\section{Nota Científica}

\author{
Sebastiana Arroyo Bote 1,a \\ 1 Universidad de las Islas Baleares, Área de la Odontología \\ Conservadora, Islas Baleares, España. \\ a Doctora en Medicina y Cirugía. \\ Correspondencia: \\ Sebastiana Arroyo Bote: 20506sab@comb.cat \\ C/ Provenza no $1324^{\circ}-1^{a}$ Barcelona 08029, España \\ ORCID: 0000-0002-5549-7697

\section{Editor:} \\ Juan Carlos Cuevas-González \\ Universidad Autónoma de Ciudad Juárez, México.
}

\section{COVID-19 laboratory tests and their implication in dental treatment}

Conflicto de intereses: los autores declaran no tener conflictos de interés.

\section{Fuente de financiamiento: autofinanciado.}

Recibido: 01/06/20

Aceptado: 09/06/20

Publicado: 04/08/20

\begin{abstract}
Resumen
Desde la identificación del virus SARS-CoV-2 como causante de la enfermedad y pandemia COVID-19, el diagnóstico de los infectados, el control de los grupos de riesgo y la inmunidad de la población han sido los principales objetivos de la comunidad científica. Son imprescindibles las pruebas de laboratorio para diagnosticar a los contagiados, determinar el estado y evolución de la enfermedad en los pacientes con clínica y la inmunidad que ha desarrollado cada grupo social. Dependiendo de los resultados de las distintas pruebas de laboratorio COVID-19, los profesionales sanitarios indican diferentes actuaciones. Los Odontólogos debemos indicar la realización de tratamientos dentales basándonos en los resultados de las pruebas de laboratorio COVID-19 dado el alto riesgo de diseminación y contagio que conllevan nuestros tratamientos.
\end{abstract}

Palabras clave: COVID-2019; SARS-CoV-2; Coronavirus; Serología (fuente: DeCS BIREME).

\begin{abstract}
Since the identification of the SARS-CoV-2 virus as the cause of the disease and the COVID-19 pandemic, the diagnosis of the infected population, the control of risk groups, and the immunity of the population have been the main objectives of the scientific community. Laboratory tests are essential to diagnose infected population, determine the status and evolution of the disease in patients with symptoms, and the immunity that each social group has developed. Depending on the results of the different COVID-19 laboratory tests, healthcare professionals indicate different actions and treatments. Dentists must take into account the results of COVID-19 laboratory tests of their patients as input before to the performance of any dental treatments, given the high risk of spread and contagion that dental treatments entail.
\end{abstract}

Keywords: COVID-2019; SARS-CoV-2; Coronavirus; Serology (source: MeSH NLM).

( ) Los autores. Este artículo es publicado por la revista Odontología Sanmarquina de la Facultad de Odontología, Universidad Nacional Mayor de San Marcos. Este es un artículo de acceso abierto, distribuido bajo los términos de la licencia Creative Commons Atribucion - No Comercia_Compartir Igual 4.0 Internacional. (http://creativecommons.org/licenses/by-nc-sa/4.0/) que permite el uso no comercial, distribución y reproducción en cualquier medio, siempre que la obra original sea debidamente citada. 


\section{Introducción}

La enfermedad COVID-19 fue identificada por primera vez en diciembre del 2019 en la ciudad de Wuhan (provincia de Hubei en China), como una neumonía de causa desconocida. Posteriormente se aisló un nuevo coronavirus SARS-CoV-2 y el 7 de enero de 2020 se le identificó como el causante de la enferme$\mathrm{dad}^{1}$. Rápidamente aparecieron nuevos casos mayoritariamente con un síndrome respiratorio agudo grave (en inglés severe acute respiratory syndrome SARS) que en algunos casos llevaron al fallecimiento de los pacientes $^{2,3}$. El alto nivel de contagio del virus, provocó que la enfermedad se expandiera en diferentes países de una forma rápida, por lo cual fue decretada por la OMS como pandemia. El diagnóstico e identificación de los pacientes COVID-19 positivos o de aquellos pacientes que han tenido contacto estrecho con enfermos de COVID-19 es fundamental para el control de la pandemia ${ }^{4}$. Existen distintas pruebas de laboratorio para el diagnóstico de la enfermedad o de los pacientes asintomáticos contagiados. Unas detectan ARN (RT- PCR) o antígenos del virus SARcov-2 (pruebas rápidas) ${ }^{5-7}$ y otras los anticuerpos generados como respuesta inmune ante el virus (pruebas serológicas). Del resultado de estos tipos de pruebas se determinará la situación en cada momento del paciente frente a la enfermedad y la actitud a seguir en cuanto a recomendaciones de aislamiento personal, tratamiento médico, y control epidemiológico de la enfermedad ${ }^{8,9}$.

En los periodos de incubación presintomáticos o en los primeros días de síntomas la carga vírica detectada mediante RT-PCR se sitúa entre $10^{4}-10^{8}$ copias de genoma/ $\mathrm{ml}$., lo que refleja una alta carga viral. En los primeros 7 días desde el inicio de los síntomas la RT-PCR es positiva en el $100 \%$ de los pacientes, reduciendo progresivamente hasta alcanzar 70\% de positividad entre los días 15-29 ${ }^{10,11}$. En los pacientes con un curso leve el mayor pico de carga viral se detecta sobre el quinto día desde el inicio de los síntomas y prácticamente desaparece al décimo día, detectando en algunos casos niveles muy bajos después del décimo día, disminuyendo mucho la carga viral lo que parece implicar una menor capacidad de contagio ${ }^{12}$. Aunque To et al, en uno de los pacientes de su estudio detectaron carga viral de ARN 25 días después de iniciarse los síntomas ${ }^{13}$.

En muestras tomadas a partir del sexto día de presencia de síntomas clínicos, en pacientes con curso leve, no se ha conseguido crecimiento del virus cuando el número detectado es inferior a $10^{5}$ copias por torunda. Este dato se ha tenido en cuenta para establecer los periodos de contagiosidad de la enfermedad ${ }^{14,15}$. Concluyendo que los pacientes asintomáticos o con curso leve de la enfermedad pueden ser fuente de contagio durante el periodo de incubación y la primera semana de signos o síntomas clínicos, en los días posteriores, aunque tengan RT-PCR positiva no se considera que tienen capacidad de contagio. Los pacientes con un curso clínico que requiere hospitalización la capacidad de contagio se mantiene desde el periodo de incubación hasta un mes del inicio de la enfermedad, y en los casos críticos la capacidad de contagio se mantiene hasta el éxitus del paciente ${ }^{16}$.

Se han detectado anticuerpos neutralizantes en el quinto día de la enfermedad, pero con títulos muy bajos, que van aumentando con el paso de los días alcanzando niveles muy altos a partir del doceavo día $(>=1 / 512){ }^{17}$. Esto explica que las pruebas serológicas serán negativas en los primeros días de la enfermedad, positivizándose unos 10 días después del inicio de la sintomatología, por lo que no son válidas para el diagnóstico de la enfermedad, solo son válidas para controlar el curso de la respuesta inmune y la prevalencia de la enfermedad en una población. Sin embargo, todavía no se sabe la cantidad necesaria de anticuerpos neutralizantes para combatir la infección del virus ${ }^{18}$

Las pruebas serológicas fundamentalmente detectan tres tipos de inmunoglobulinas: IgA, IgM e IgG. Las IgA tienen mayor sensibilidad y se detectan bastante pronto en la respuesta frente al virus, pero hay pocos estudios al respecto y pocas técnicas que las detecten ${ }^{19}$. Las IgM suelen detectarse a partir del séptimo día de la sintomatología, pero es entre el doceavo y catorceavo día cuando es detectable en el $94 \%$ de los pacientes ${ }^{18}$. Las IgG se detectan mayoritariamente sobre la tercera semana.

Las pruebas que detectan los anticuerpos generados por el sistema inmune del paciente frente al virus SARSCov-2 pueden clasificarse en pruebas rápidas sin necesidad de laboratorio o pruebas que requieren laboratorio y personal entrenado. La sensibilidad y fiabilidad de las pruebas rápidas es baja por lo que debido al alto número de falsos negativos y positivos no son muy recomendables, además no suelen especificar el título y tipo de anticuerpo. La prueba de laboratorio para detección de anticuerpos frente al virus SARS-Cov-2 más utilizada es la que se realiza mediante Ensayo de Inmunoabsorción ligado a Enzimas (ELISA), con esta prueba de laboratorio podemos obtener un resultado de mayor fiabilidad y sensibilidad obteniendo el título, tipo y subtipos de inmunoglobulinas que se han generado frente al virus. Esta prueba es la que se considera adecuada para el estudio de la inmunidad individual y/o de la población frente al virus SARS-CoV-2 y en combinación con la RT-PCR para controlar la evolución de la enfermedad en los pacientes infectados ${ }^{20}$.

La Odontología ha tenido que adaptar sus protocolos de actuación para garantizar la bioseguridad de los tratamientos dentales. La posible presencia del virus en la boca de los pacientes, la generación de aerosoles durante los tratamientos dentales y la necesidad de proximidad entre el paciente y el equipo dental han requerido extremar los métodos de barreras en los tratamientos odontológicos (mascarillas FFP2, gafas herméticas, pantallas protectoras, gorros, uniformes de manga larga impermeables y la utilización de doble guante) así como implementar los métodos de limpieza y desinfección del gabinete dental y del resto de las instalaciones del consultorio ${ }^{4,21-23}$. Es imprescindible realizar un triaje de los pacientes antes de ser atendidos en la consulta dental. Se han realizado distintos cuestionarios para detectar casos asintomáticos o leves de 
COVID-19, basados fundamentalmente en los síntomas que ha podido presentar el paciente, así como en su relación o contacto con pacientes infectados con el virus SARS-CoV-2. Debiendo posponer los tratamientos si el paciente responde positivamente a alguna de las preguntas realizadas en el triaje. Si el paciente no presenta fiebre ni es sospechoso de poder haber estado en contacto con el virus podrá someterse a tratamientos dentales. Deberá realizarse desinfección de la cavidad oral antes de iniciar el tratamiento dental, para ello el enjuague con peróxido de hidrógeno al $1 \%$ o povidona yodada al $0,2 \%$ son las soluciones aconsejadas ${ }^{22}$. La utilización del dique de goma y la implementación de los sistemas de aspiración pueden reducir la contaminación generadas por los aerosoles. La utilización de técnicas sencillas y rápidas son aconsejables para reducir las posibilidades de contagio y diseminación de gérmenes ${ }^{24}$.

A pesar de todas las medidas de prevención y detección de pacientes infectados mediante el triaje, podemos estar ante enfermos asintomáticos infectados que se sometan a tratamientos dentales, por lo que la mejor manera de detectar el estado de los pacientes son las pruebas de laboratorio. En esta nota científica se exponen mediante algoritmos los distintos tipos de pruebas para el diagnóstico de la enfermedad (Figura 1), la RT-PCR (Figura 2), y las pruebas serológicas (Figura 3), realizando una tabla que indica la implicación de las pruebas de laboratorio en la decisión de realizar tratamientos dentales (Tabla).

\section{Cuerpo de la nota}

En la tabla se presenta la exposición de los distintos resultados de las pruebas de laboratorio, indicando la situación del paciente respecto a la enfermedad COVID-19 y la situación respecto a la indicación de realizar tratamientos dentales.

\section{Conclusiones}

El odontólogo debe conocer la enfermedad y reconocer a los enfermos o infectados por el SARS-CoV-2, así como implementar las medidas de seguridad en los tratamientos dentales ${ }^{21}$. Basándonos en la carga vírica, la posibilidad de crecimiento del virus y la respuesta inmune se ha creado la tabla que muestra las distintas posibilidades de resultados de las pruebas de laboratorio y su significado clínico en relación con la posibilidad de contagio y de enfermedad clínica, estableciendo los pacientes que pueden ser sometidos a tratamientos dentales sin restricciones, que son aquellos que han superado la enfermedad o bien no la tienen, pudiendo realizar tratamientos con aerosol siempre que apliquemos los medidas de protección establecidas por los protocolos en el momento de su realización. Los pacientes infectados, (asintomáticos o no) con RT-PCR + no deben ser tratados porque deben ser aislados en cuarentena. Los pacientes con RT-PCR- pero con $\operatorname{IgM}+$, podrían tratarse pero todavía están en periodo de recuperación o en la fase final de la enfermedad, por lo que se considera que pueden tener el virus pero con tasas muy bajas sin
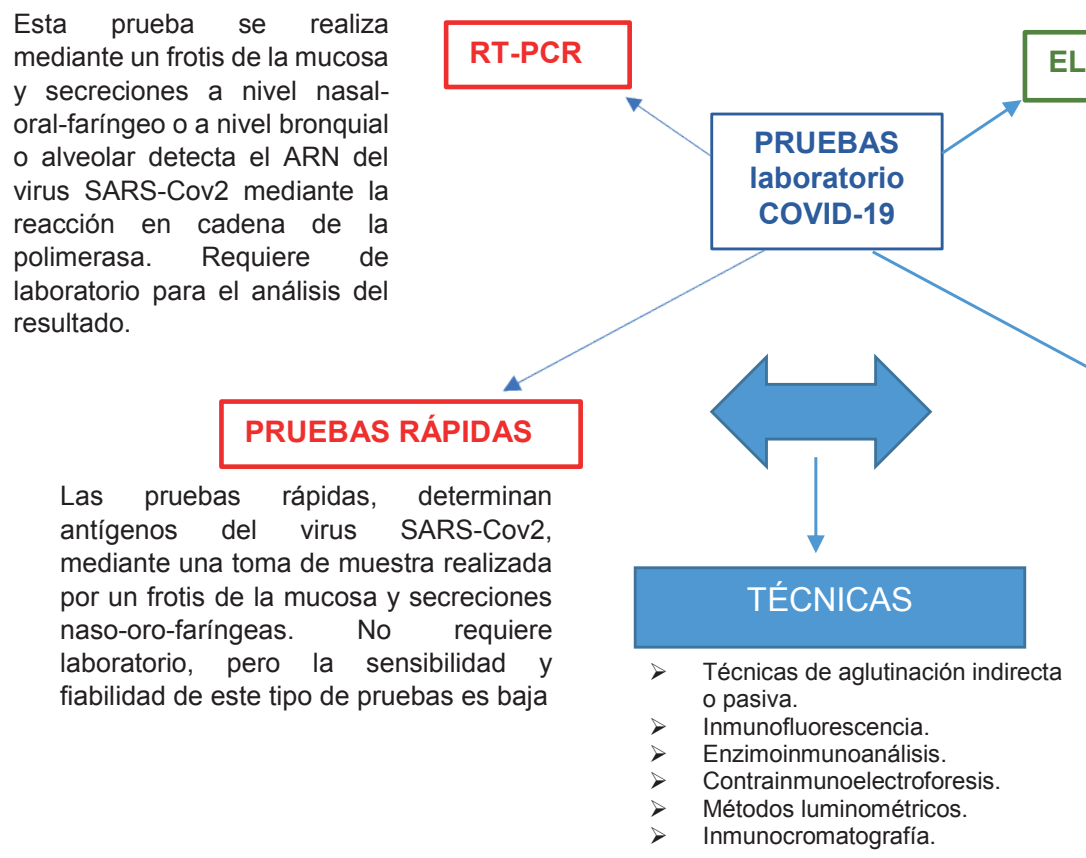

Figura 1. Pruebas de laboratorio utilizadas para el diagnóstico de la enfermedad COVID-19
Esta prueba se realiza mediante una extracción sanguínea por venopunción. Detecta el tipo, subtipo y título de los anticuerpos generados frente al virus SARS-Cov2, mediante Ensayo de inmunoabsorción ligado a enzimas. Requiere de laboratorio
Las pruebas rápidas, determinan anticuerpos generados frente el virus SARS-Cov2, mediante una toma de muestra realizada por una punción digital y el análisis de una gota de sangre capilar. No requiere laboratorio. La sensibilidad de este tipo de pruebas es baja o pasiva.

Enzimoinmunoanalisis.

Contrainmunoelectrofores

Inmunocromatografía. 


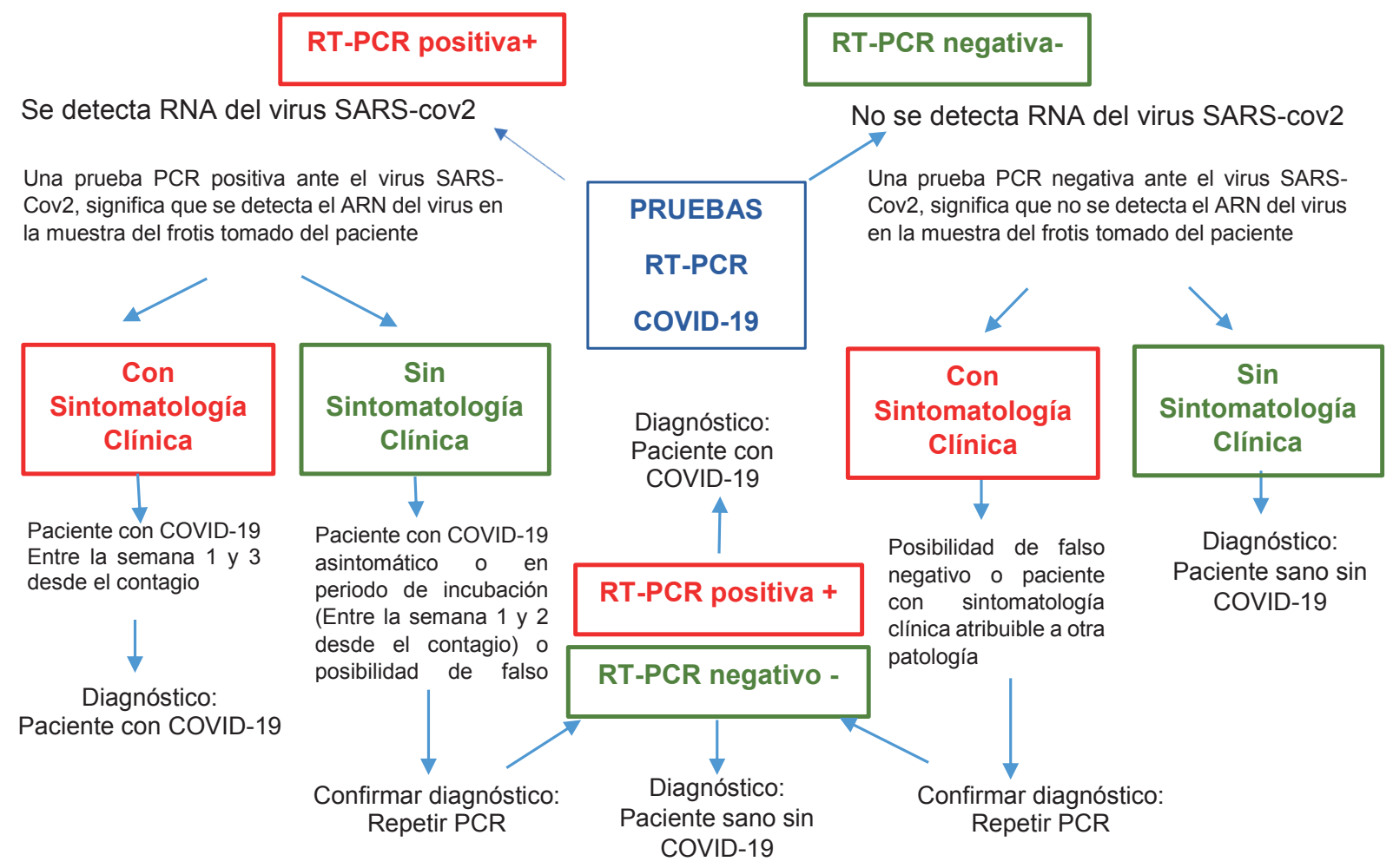

Figura 2. Prueba de laboratorio RT-PCR para el diagnóstico de la enfermedad COVID-19

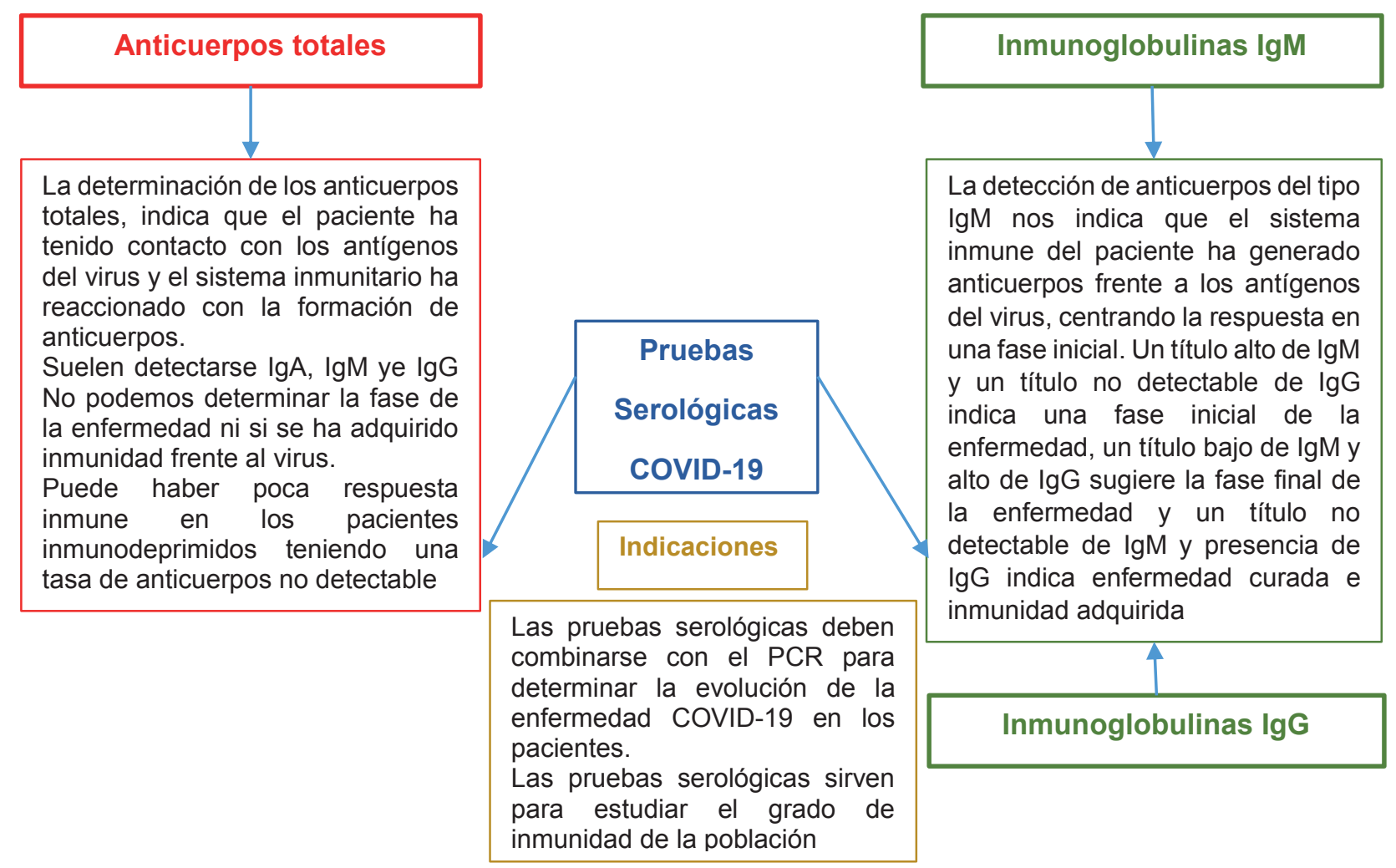

Figura 3. Pruebas de serología para el diagnóstico de la enfermedad COVID-19 
Tabla. Decisión de tratamiento dental en función del resultado de las pruebas de laboratorio

\begin{tabular}{|c|c|c|c|c|c|}
\hline RT-PCR & $\begin{array}{l}\text { ANTICUERPOS } \\
\text { TOTALES }\end{array}$ & ELISA IgM & ELISA IgG & SIGNIFICADO CLÍNICO & DECISIÓN DENTAL \\
\hline RT-PCR + & $\begin{array}{l}\text { ANTÍCUERPOS } \\
\text { TOTALES - }\end{array}$ & $\begin{array}{l}\text { ANTICUERPOS } \\
\text { IgM- }\end{array}$ & $\begin{array}{l}\text { ANTICUERPOS } \\
\text { IgG - }\end{array}$ & $\begin{array}{l}\text { PACIENTE EN PRIMEROS ESTADIOS DE LA } \\
\text { ENFERMEDAD O EN PERIODO DE } \\
\text { INCUBACIÓN }\end{array}$ & $\begin{array}{l}\text { NO REALIZAR TRATAMIENTO } \\
\text { ODONTOLÓGICO }\end{array}$ \\
\hline RT-PCR + & $\begin{array}{l}\text { ANTÍCUERPOS } \\
\text { TOTALES + }\end{array}$ & $\begin{array}{l}\text { ANTICUERPOS } \\
\text { IgM+ }\end{array}$ & $\begin{array}{l}\text { ANTICUERPOS } \\
\text { IgG - }\end{array}$ & $\begin{array}{l}\text { PACIENTE ENTRE LA 2-3 SEMANA DE LA } \\
\text { ENFERMEDAD }\end{array}$ & $\begin{array}{l}\text { NO REALIZAR TRATAMIENTO } \\
\text { ODONTOLÓGICO }\end{array}$ \\
\hline RT-PCR + & $\begin{array}{l}\text { ANTÍCUERPOS } \\
\text { TOTALES + }\end{array}$ & $\begin{array}{l}\text { ANTICUERPOS } \\
\text { IgM+ }\end{array}$ & $\begin{array}{l}\text { ANTICUERPOS } \\
\operatorname{IgG}+\end{array}$ & $\begin{array}{l}\text { PACIENTE ENTRE 3-4 SEMANA DE LA } \\
\text { ENFERMEDAD CON PROBABILIDAD DE } \\
\text { CONTAGIO }\end{array}$ & $\begin{array}{l}\text { NO REALIZAR TRATAMIENTO } \\
\text { ODONTOLÓGICO HASTA } \\
\text { NEGATIVIZAR PCR }\end{array}$ \\
\hline RT-PCR - & $\begin{array}{l}\text { ANTÍCUERPOS } \\
\text { TOTALES + }\end{array}$ & $\begin{array}{l}\text { ANTICUERPOS } \\
\text { IgM+ }\end{array}$ & $\begin{array}{l}\text { ANTICUERPOS } \\
\operatorname{IgG}+\end{array}$ & $\begin{array}{l}\text { PACIENTE ENTRE 3-4 SEMANA DE LA } \\
\text { ENFERMEDAD CASI NULA PROBABILIDAD DE } \\
\text { CONTAGIO }\end{array}$ & $\begin{array}{l}\text { REALIZAR TRATAMIENTOS } \\
\text { DENTALES NO INAPLAZABLES } \\
\text { URGENCIA DENTAL }\end{array}$ \\
\hline RT-PCR - & $\begin{array}{l}\text { ANTÍCUERPOS } \\
\text { TOTALES + }\end{array}$ & $\begin{array}{l}\text { ANTICUERPOS } \\
\text { IgM- }\end{array}$ & $\begin{array}{l}\text { ANTICUERPOS } \\
\text { IgG }+\end{array}$ & $\begin{array}{l}\text { PACIENTE QUE HA SUPERADO LA } \\
\text { ENFERMEDAD Y ESTÁ INMUNIZADO }\end{array}$ & $\begin{array}{l}\text { REALIZAR TRATAMIENTOS } \\
\text { ODONTOLÓGICOS UTILIZANDO } \\
\text { PROTOCOLOS COVID-19 }\end{array}$ \\
\hline RT-PCR - & $\begin{array}{l}\text { ANTÍCUERPOS } \\
\text { TOTALES - }\end{array}$ & $\begin{array}{l}\text { ANTICUERPOS } \\
\text { IgM- }\end{array}$ & $\begin{array}{l}\text { ANTICUERPOS } \\
\text { IgG - }\end{array}$ & $\begin{array}{l}\text { PACIENTE QUE NO HA TENIDO CONTACTO } \\
\text { CON EL VIRUS Y NO ESTÁ INMUNIZADO }\end{array}$ & $\begin{array}{l}\text { REALIZAR TRATAMIENTOS } \\
\text { ODONTOLÓGICOS UTILIZANDO } \\
\text { PROTOCOLOS COVID-19 }\end{array}$ \\
\hline
\end{tabular}

RT-PCR: Reacción en cadena de la Polimerasa. RT-PCR+: Prueba Reacción en cadena de la Polimerasa positiva. RT-PCR-: Prueba Reacción en cadena de la Polimerasa negativa. ELISA: Ensayo de Inmunoabsorción ligado a Enzimas. IgM+: Inmunoglobulina M detectable en test ELISA. IgM-: Inmunoglobulina M no detectable en test ELISA. IgG+: Inmunoglobulina G detectable en test ELISA. IgG-: Inmunoglobulina G no detectable en test ELISA.

capacidad de contagio, o bien ser un falso negativo, por lo que es aconsejable esperar a que las IgM se negativicen y hayan pasado 15 días desde el alta de la enfermedad, pero en caso de extrema urgencia podría realizarse un tratamiento dental paliativo sin aerosol bajo extremas medidas de bioseguridad. Podemos concluir que los pacientes pueden someterse a tratamiento dental siempre que no sean fuente de contagio, debiendo posponer los tratamientos en los pacientes con RT-PCR+ aunque hayan desarrollado anticuerpos y estén asintomáticos, indicando la realización de tratamientos dentales solo en los pacientes que han negativizado la RT-PCR.

\section{Referencias bibliográficas}

1. Huang C, Wang Y, Li X, Ren L, Zaho J, Hu Y, et al. Clinical features of patients infected with 2019 novel coronavirus in Wuhan, China. Lancet 2020;395(10223):497506. DOI: $10.1016 / S 0140-6736(20) 30183-5$

2. Zhao Y, Zhao Z, Wang Y, Zhou Y, Ma Y y Zuo W. Single-cell RNA expression profiling of ACE2, the putative receptor of Wuhan 2019-nCov. bioRxiv [Internet] 2020.01.26.919985; [citado el 18 de mayo de 2020] Disponible en: https://www.biorxiv.org/content/10.1101/2020.01.26.919985v1.full.pdf. $\quad$ DOI: 10.1101/2020.01.26.919985.

3. Guan W, Ni Z, Hu Y, Liang W, Ou C, He J, et al. Clinical characteristics of 2019 novel coronavirus infection in China. N Engl J Med 2020; 382(18):1708-1720. DOI: 10.1056/NEJMoa2002032

4. Morales Navarro D. Acciones del personal de salud del área estomatológica en relación al COVID-19. $\mathrm{Rev} \mathrm{Cu}-$ bana Estomatol [Internet]. 2020 [citado el 4 de junio de 2020];57(1): pp. e3245. Disponible: http://www.revestomatologia.sld.cu/index.php/est/article/view/3245
5. Instituto Catalan Salud. Algoritme de seguiment dels pacients COVID-19 a l'AP. Barcelona: Departament de Salut; 2020. Col.lecció especial COVID-19 [245]. Disponible en: https://scientiasalut.gencat.cat/handle/11351/4811

6. Marty F, Chen $\mathrm{K}$ y Verrill K. How to Obtain a Nasopharyngeal Swab Specimen. N Engl J Med [Internet].2020 [Citado el 30 de mayo]; 382(22):e76. Disponible: https://www.nejm.org/doi/pdf/10.1056/ NEJMvcm2010260?articleTools=true. DOI: 10.1056/ NEJMvcm2010260

7. Wölfel R, Corman V, Guggemos W, Seilmaier M, Zange S, Müller M, et al. Virological assessment of hospitalized patients with COVID-2019 Nature 2020; 581:465-469. DOI:10.1038/s41586-020-2196-x

8. Waite House. Guidance on: Interpreting Covid-19 test results 2020. Disponible en:https://www.whitehouse.gov/ wp-content/uploads/2020/05/Testing-Guidance.pdf

9. González Escribano F, Martínez Cáceres E, López Hoyos M y González Fernández A. Anticuerpos anti-SARSCoV-2 Actualización SEI. Informe de la Sociedad Española de Inmunología Madrid: SEI; 2020 Versión 02/ 14 abril Disponible en: https://www.inmunologia.org/ Upload/Documents/1/5/2/1529.pdf

10. Liu Y, Yan L M, Wan L, Xiang TX, Le A, Liu JM, et al. Viral dynamics in mild and severe cases of COVID-19. Lancet Infect Dis. 2020 Jun; 20(6):656-657. DOI: $10.1016 / S 1473-3099(20) 30232-2$

11. Wang D, Hu B, Hu C, Zhu F, Liu X, Zhang J, et al. Clinical Characteristics of 138 Hospitalized Patients With 2019 Novel Coronavirus-Infected Pneumonia in Wuhan, China. JAMA 2020;323(11):1061-1069. DOI:10.1001/jama.2020.1585 
12. Pan $Y$, Zhang D, Yang P, Poon L y Wang Q. Viral load of SARS-CoV-2 in clinical samples. Lancet Infect Dis 2020;20(4):410-411. DOI: 10.1016/S14733099(20)30114-6.

13. To K, Tsang O, Leung W, Tam A, Wu T, Lung D, et al. Temporal profiles of viral load in posterior oropharyngeal saliva samples and serum antibody responses during infection by SARS-CoV-2: an observational cohort study. Lancet Infect Dis. 2020;20(5):565-574. DOI: 10.1016/ S1473-3099(20)30196-1

14. Centro Europeo para la prevención y el Control de las enfermedades. Coronavirus disease 2019 (COVID-19) in the EU/EEA and the UK - ninth update, 23 April 2020. Stockholm: ECDC; 2020 [Internet] [Citado el 20 de mayo de 2020]. Disponible en: https:/www.ecdc.europa. $\mathrm{eu} / \mathrm{en} /$ publications-data/rapid-risk-assessment-coronavirus-disease-2019-covid-19-pandemic-ninth-update

15. Organización Mundial Salud. Coronavirus disease 2019 (COVID-19) Situation Report - 73 February 2020 [Internet]. Geneva [Citado el 30 de abril de 2020]. Disponible en: https://www.who.int/docs/default-source/coronaviruse/situation-reports/20200402-sitrep-73-covid 19.pdf?sfvrsn=5ae25bc7_2, 2020.

16. Li Q, Guan X, Wu P, Wang X, Zhou L, Tong Y, et al. Early Transmission Dynamics in Wuhan, China, of Novel Coronavirus-Infected Pneumonia. N Engl J Med 2020;382:1199-1207. DOI: 10.1056/NEJMoa2001316

17. Wu F, Wang A, Liu M, Wang Q, Chen J, Xia S, et. al. Neutralizing antibody responses to SARS-CoV-2 in a COVID-19 recovered patient cohort and their implications. medRxiv [Internet]. 2020 [Citado el 4 de mayo de 2020]; 382:1199-1207 Disponible en: https://www.medrxiv.org/content/10.1101/2020.03.30.20047365v1. full.pdf. DOI:10.1101/2020.03.30.20047365

18. Zhao J, Yuan Q, Wang H, Liu W, Liao X, Su Y, Wang $\mathrm{X}$, et al. Antibody responses to SARS-COV-2 of patients with novel coronavirus disease 2019. Clin Infect Dis [Internet]. 2020 [Citado el 20 de mayo de 2020]; ciaa344. Disponible en: https://pubmed.ncbi. nlm.nih.gov/32221519/. DOI:10.1093/cid/ciaa344
19. Okba N, Müller M, Li W, Wang C, GeurtsvanKessel C, Corman V, y et al. SARS-CoV-2 specific antibody responses in COVID-19 patients. medRxiv [Internet]. 2020.03.18. 20038059; [Citado el 30 de abril de 2020]. Disponible en: https://www.medrxiv.org/content/10.1101/2020.03.18.20038059v1. DOI:10.1101/2020.03.18.20038059

20. García Collía M, García Martínez D, Carbajal de Lara JA, Albert Hernández M, Al Cassan Martínez D y Salinas M. Diagnóstico por el laboratorio del virus SARSCoV-2 agente de la infección Covid-19. Vocalía Nacional de Analistas Clínicos, Consejo general de Farmaceuticos [Internet]. 2020 [Citado el 20 de mayo de 2020] Disponible en: https://www.portalfarma.com/Profesionales/ campanaspf/Asesoramiento-salud-publica/infeccion-coronavirus-2019-nCoV/Documents/informe-diagnostico-sars-cov-2.pdf

21. Suaste Olmos F, Cuevas González M, García Calderón A y Cuevas González J. Conociendo al COVID-19 y la labor odontológica ante la pandemia. Odontol Sanmarquina 2020;23(2):101-104. DOI:15381/os.v23i2.17753, 2020 .

22. Robles D, Rodríguez Casanovas H. «El COVID-19 y la consulta dental: información y consejos,» Gaceta Dental [Internet]. 18 de marzo 2020 [Citado el 30 de abril de 2020]. Disponible en: https://gacetadental. com/2020/03/el-covid-19-y-la-consulta-dental-informacion-y-consejos-95967/

23. Ministerio de Sanidad Govierno de España e Instituto de Salud Carlos III, Estrategia de diagnóstico, vigilancia y control en la fase de transmisión de la pandemia de Covid-19. [Internet].2020 12 de mayo [Citado el 20 de mayo de 2020] Disponible en: https://www.mscbs. gob.es/profesionales/saludPublica/ccayes/alertasActual/ nCov-China/documentos/COVID19_Estrategia_vigilancia_y_control_e_indicadores.pdf

24. Arroyo Bote S. Soluciones a nuevos retos de bioseguridad en el tratamiento dental. 2020 Nobel biocare-kerr [Internet]. [Citado el 14 de mayo de 2020]. Disponible en: https://readytalk.webcasts.com/viewer/event.jsp?ei=1317167\&tp_key=a60152b5b1 